\title{
59. POSTMAGMATIC TEXTURES AND FABRICS OF GABBROS AND PERIDOTITES FROM DSDP SITE 334
}

\author{
Herwart Helmstaedt, Department of Geological Sciences, Queen's University, Kingston, Ontario, Canada
}

\section{INTRODUCTION}

Eight samples from the gabbro-peridotite sequence encountered at Site 334 were examined for signs of postmagmatic deformation and metamorphic changes. The clinopyroxene and amphibole fabrics of a metagabbro $(22-1,37-45 \mathrm{~cm})$ were studied in detail, and the magnitude of strain was estimated using the centerpoint method (Ramsay, 1967).

Following DeRoever (1956), numerous workers proposed that ophiolite sequences in orogenic belts may represent tectonically emplaced fragments of oceanic crust. Thayer (1969), in particular, drew attention to the possibility that peridotite-gabbro complexes may be keys to the petrology of mid-oceanic ridges and pointed out the problem of distinguishing textures present before and after the tectonic emplacement of such complexes. Samples from the gabbro-peridotite section of Site 334 provide the unique opportunity to study effects of ocean-floor metamorphism and deformation near the ridge prior to any modification or obliteration by orogenic regional metamorphism.

\section{FABRIC AND STRAIN}

\section{Gabbros}

The petrographic and textural descriptions of the samples are summarized in Table 1. Samples 21-1, 98 $\mathrm{cm} 23-1,8-22 \mathrm{~cm}$ are virtually unaltered. The minerals of Sample 21-1, 100-107 cm show faint undulatory extinction which is probably a consequence of deformation. Incipient hydrous alteration is indicated by small amounts of pale green amphibole that fill regularly spaced microfractures in plagioclase and pyroxenes and replaces the margins of pyroxenes along the fracture margins. Although its original igneous texture is still intact, olivine gabbro Sample 26-2, 56-71 cm exhibits considerably more plastic strain in the form of undulatory extinction in all minerals, extinction bands in olivine, and some broad kink bands in pyroxenes and plagioclase. Mesoscopically, a very faint planar fabric that is nearly parallel to the core axis can be recognized. Secondary hydrous alteration minerals are common (Table 1).

In sharp contrast to the other samples, Sample 22-1, $37-45 \mathrm{~cm}$ can be classified as metagabbro showing the strong metamorphic banding typical of "Flaser gabbros." Mesoscopically, this fabric is accentuated by brown streaks of a relatively high birefringent, slightly biaxial, optically negative phyllosilicate, probably a vermiculite. The orientation of the planar fabric as constructed from its intersection with three mutually perpendicular surfaces is represented in Figure 1.
Microscopically, the rock consists of highly deformed, augen-shaped porphyroclasts of plagioclase, clinopyroxene, and othropyroxene surrounded by their anhydrous recrystallization products, the alignment of which in "pressure shadows" gives rise to the planar fabric. Pale green amphibole, both replacing the pyroxene porphyroclasts as well as growing in pressure shadows and in the matrix, shows a pronounced alignment parallel to the mesoscopic fabric. The brown phyllosilicate, though occurring in aligned zones, does not show a preferred orientation.

Orientation diagrams of the optic vibration directions of recrystallized clinopyroxenes and amphiboles are presented in Figures 2 to 4 . C-axes diagrams could not be prepared due to the paucity of cleavage in the clinopyroxenes and amphiboles. The amphibole fabric is more homogeneous than the clinopyroxene fabric and shows a good correspondence to the planar fabric (Figures 2 and 4). A c-axes maximum can be assumed to lie in the center of the $\gamma$-concentration of Figure 2f, almost parallel with the planar fabric. Subfabrics of the clinopyroxene show strong $\gamma$-concentrations (Figure 3), but the broad $\gamma$-girdle of the overall fabric (Figure 2c) does not show an obvious relationship to the planar fabric.

A strain estimate was attempted using the centerpoint method of Ramsay (1967, p. 195). When applying this method to meta-igneous rocks, a random igneous fabric with roughly equal distances between minerals must be assumed. The distances between nearest porphyroclasts were measured on a thin section photograph and plotted against their angle with a reference direction (Figure 5). Ideally, the plane of measurement should be perpendicular to the fabric, but the condition of the sample did not permit such additional cut. The directions of maximum and minimum elongation in the plane of measurement are plotted on Figure 1. Combining this result with the amphibole fabric (Figure 2f), it can be concluded that the obtained maximum elongation direction lies very close to the long axis of the deformation ellipsoid. The fabric is that of an L-S tectonite. The ratio of maximum to minimum elongation (4.1:1, see Figure $5 \mathrm{~b}$ ) is considered to be a minimum estimate (W.M. Schwerdtner, personal communication).

\section{Peridotites}

Some postigneous plastic strain is indicated by kink bands in olivine remnants of Samples 22-2, $79 \mathrm{~cm}$ and $22-2,85-88 \mathrm{~cm}$, but synkinematic recrystallization textures were not detected. Most small olivine remnants within large serpentinized grains show uniform extinction, indicating the absence of appreciable penetrative 
TABLE 1

Postmagmatic Textural History of Gabbros and Peridotites from Site 334

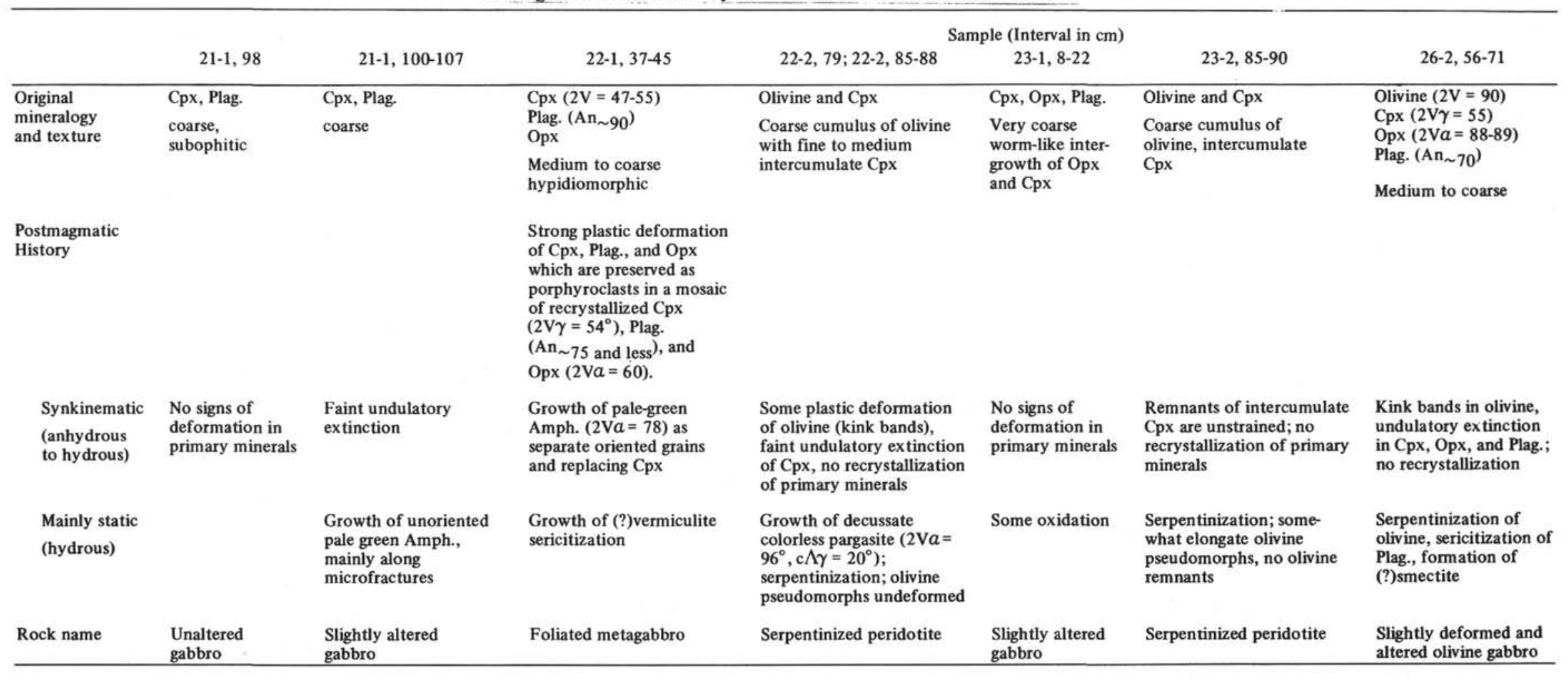




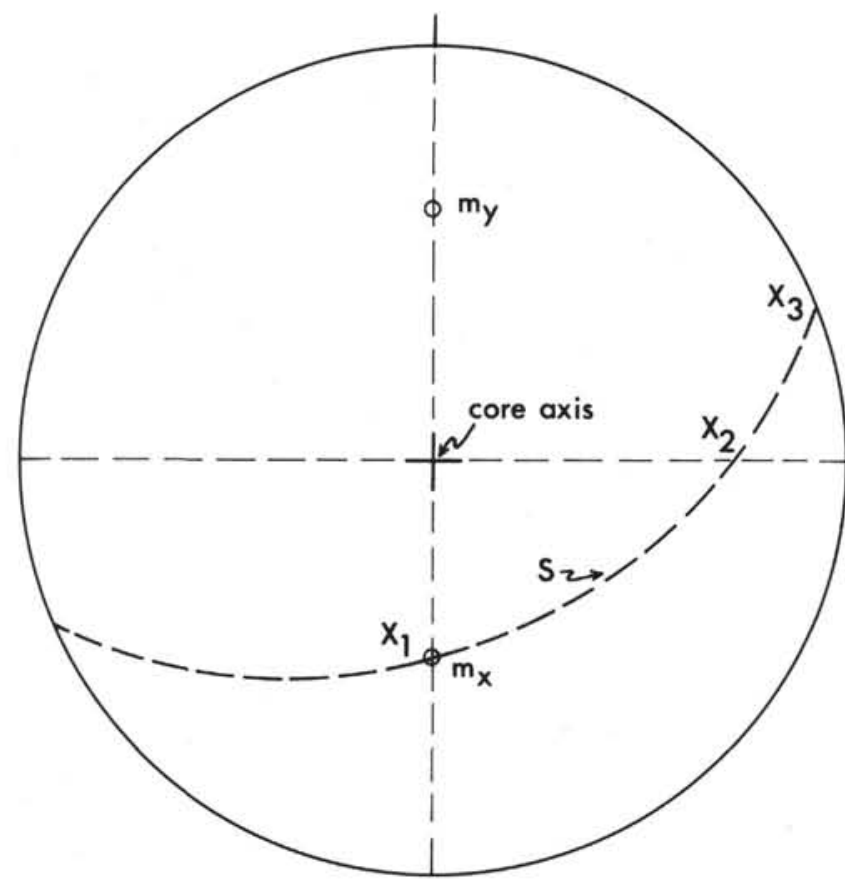

Figure 1. Lower hemisphere projection illustrating orientation of mesoscopic planar fabric of Sample 22-1, 37-45 $\mathrm{cm} . m_{x}$ and $m_{y}$ are maximum and minimum elongation directions measured in thin section parallel to core axis (see Figure 5). strain following serpentinization. The decussate texture of the pargasite suggests that also the growth of this mineral, which preceded serpentinization, was mainly static. The outlines of completely serpentinized olivine pseudomorphs in Sample 23-2, $85-90 \mathrm{~cm}$ are slightly "flattened" within a plane nearly parallel to the core axis. Whether this is a reflection of an original inequidimensional shape of the olivines or due to tectonic flattening after serpentinization is not clear. Clinopyroxene remnants in this sample are unstrained.

\section{CONCLUSIONS}

Sample 22-1, 37-45 cm has undergone an early stage of anhydrous synkinematic recrystallization followed by hydrous synkinematic recrystallization. The discrepancy between clinopyroxene and amphibole fabrics suggests a slight rotation of strain axes during deformation. Static hydrous alteration postdates the synkinematic stage.

The recrystallization of the orthopyroxene and clinopyroxene indicates temperatures of the granulite facies during the early stages of deformation which probably took place shortly after intrusion. It is probable that this deformation occurred at a depth greater than the $1.5 \mathrm{~km}$ assumed by Bonatti et al. (1975) for metagabbros transitional between the greenschist and amphibolite facies. The continued deformation under
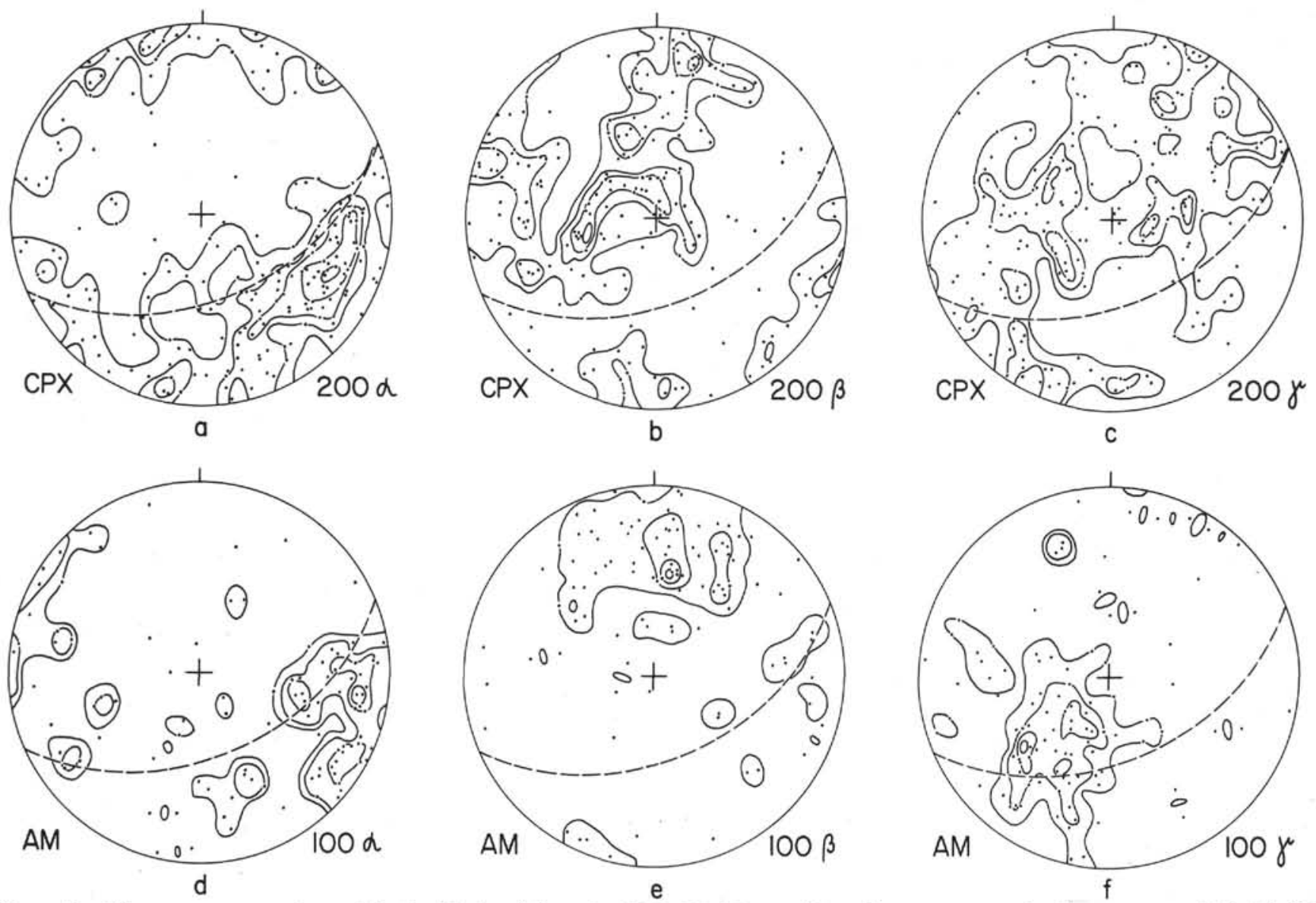

Figure 2. Clinopyroxene and amphibole fabric of Sample 22-1, $37-45 \mathrm{~cm}$. First three contours in diagrams are: 1\%, 2\%, 3\% per $1 \%$ area. Next contours: $4 \%, 6 \%$ (a); $4 \%$ (b). Contours in diagrams: $2 \%, 3 \%, 5 \%, 7 \%$ (d);2\%, $5 \%, 7 \%, 9 \%$ (e); $2 \%, 4 \%$, $6 \%, 8 \%(\mathrm{f})$. 

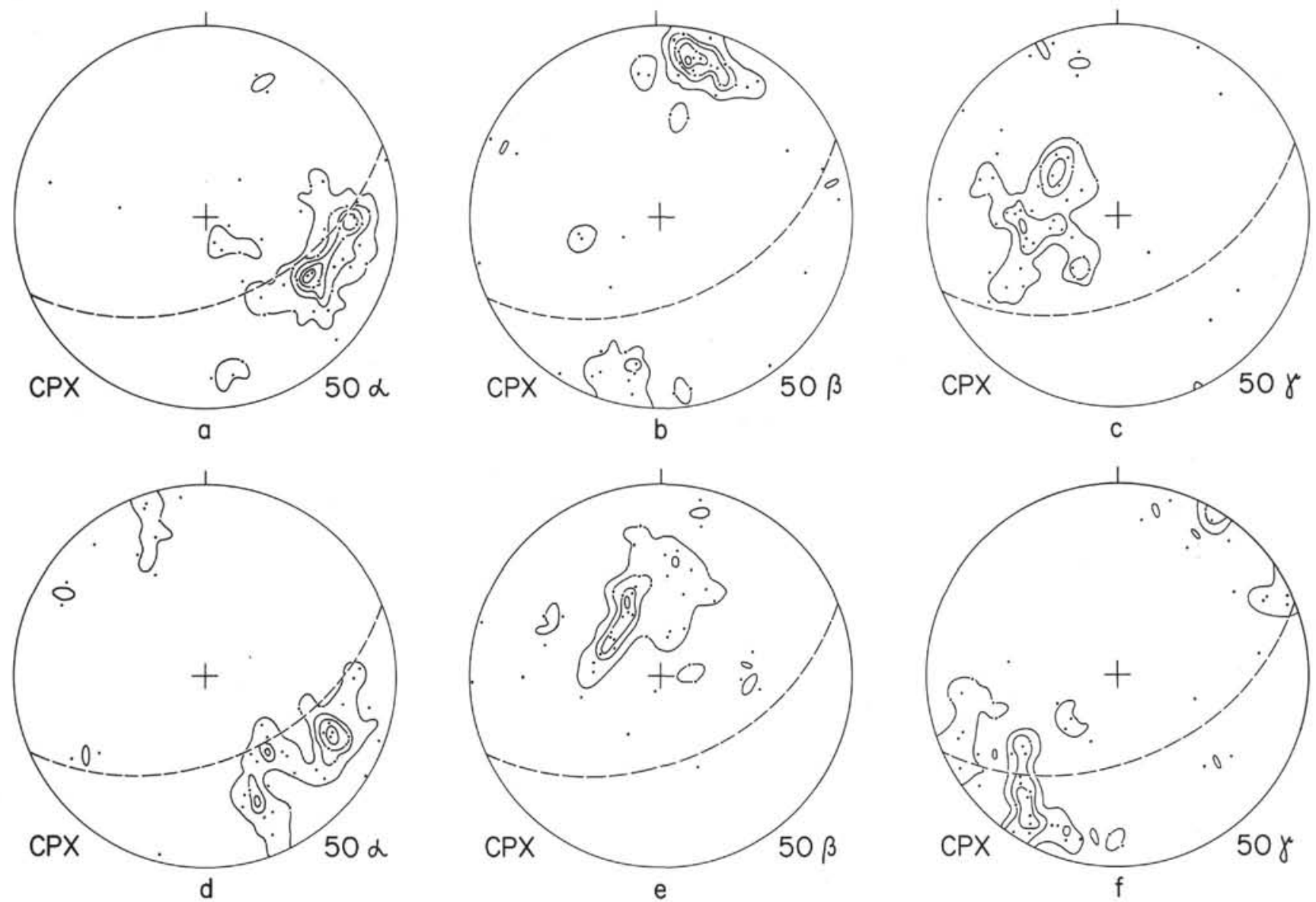

Figure 3. Clinopyroxene fabrics of subareas 1 (a-c) and 2 (d-f) (see Figure 5).First three contour in all diagrams: $4 \%, 8 \%, 10 \%$ per $1 \%$ area. Next contours: $12 \%, 14 \%$ (a); $16 \%, 18 \%$ (b); $14 \%$ (d and e). 

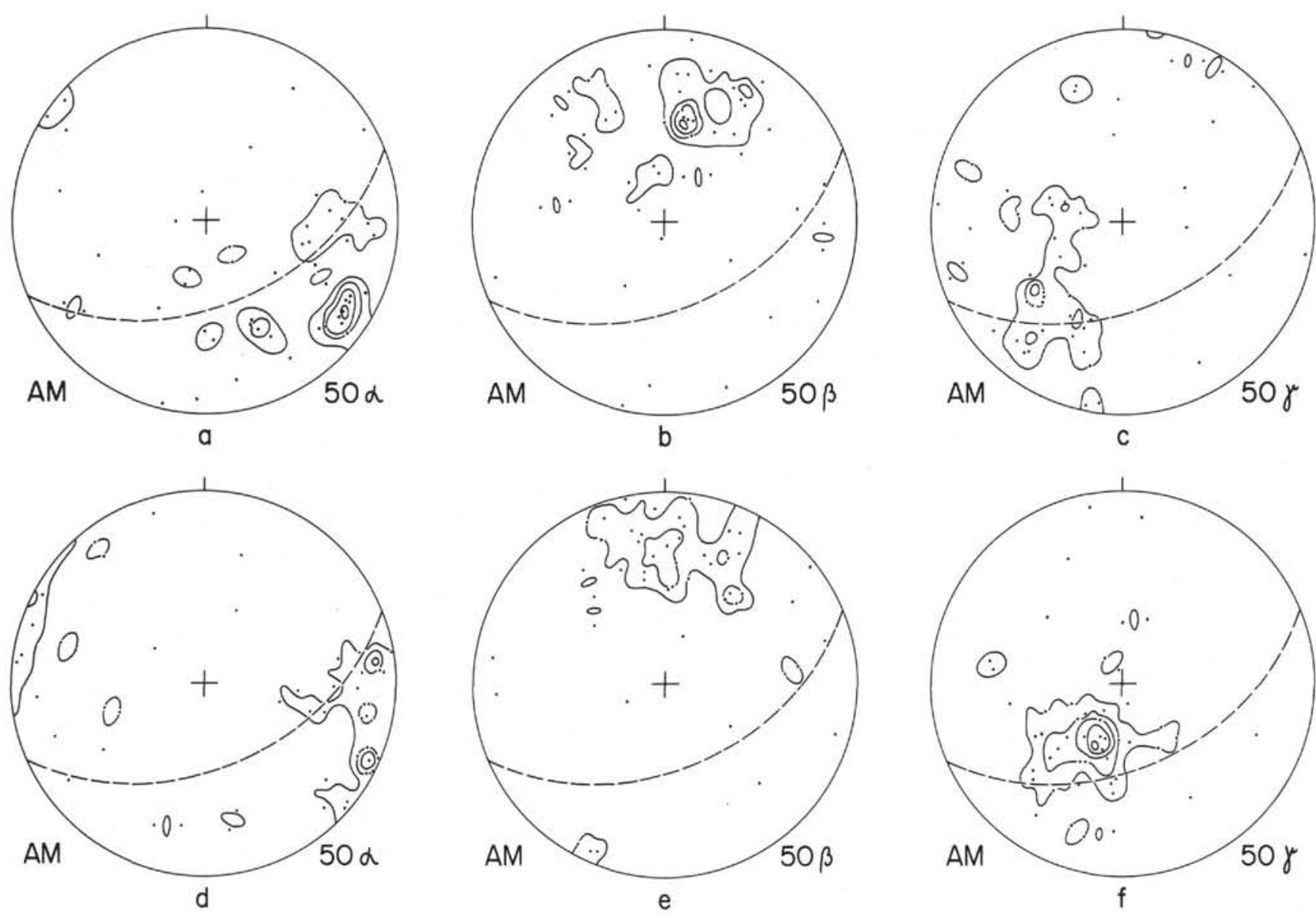

Figure 4. Amphibole fabrics of subareas 3 (a-c) and 4 (d-f). First contours in all diagrams: $4 \%, 8 \%, 10 \%$. Next contours: $14 \%$ (a); $12 \%$ (b); $12 \%, 14 \%$ (f). 


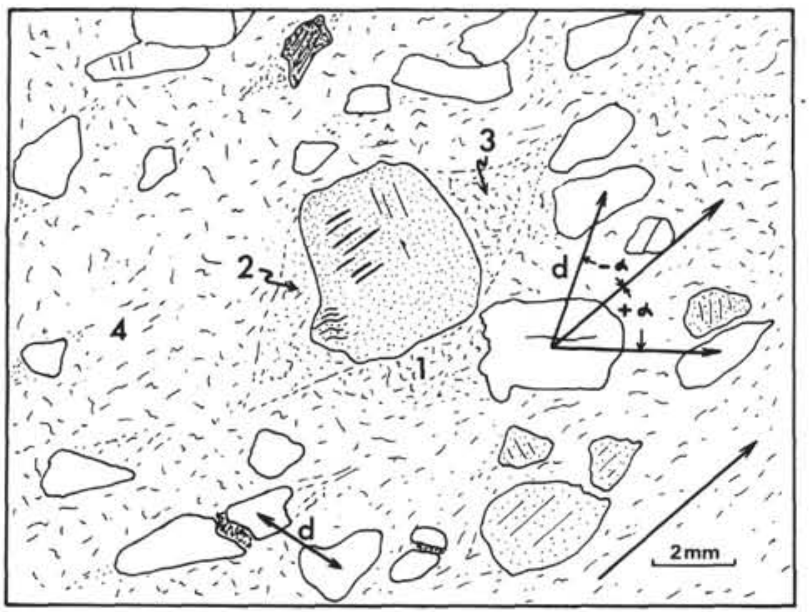

A

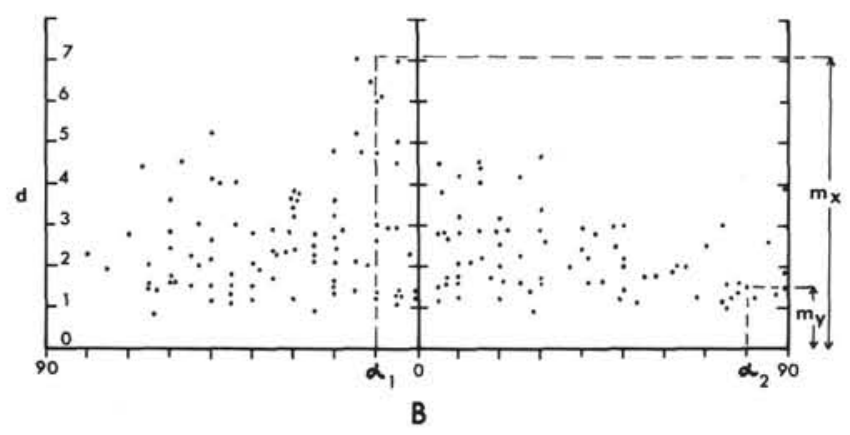

Figure 5. (A) Sketch of thin section Sample 22-1, $37-45 \mathrm{~cm}$ illustrating the center-point method for measuring strain. $d=$ distance between centers of nearest porphyroclasts; $a=$ angle with reference direction (arrow in lower right corner). 1, 2, 3, 4 = subareas of fabric diagrams (see Figures 3 and 4. (B) Plot of $d$ versus $\alpha$ showing orientation of maximum and minimum elongation direction $(\alpha 1$ and $\alpha 2)$ and ratio $m_{x} / m_{y}$.

amphibolite facies conditions may reflect the rise to higher crustal levels.

Penetrative strain was highly localized in the gabbroperidotite sequence, but the difference in degree of deformation cannot be used as a clue for the age relationships between gabbros and peridotites. Observed textures and inhomogeneous strain resemble situations described from Alpine-type peridotitegabbro complexes by Thayer $(1967,1969)$, where the relationships between gabbros and peridotites are complex and contradictory.

The serpentinization of the peridotite samples probably postdates the bulk of the penetrative strain of the metagabbro. These rocks are close together in situ $(<10$ $\mathrm{m}$ ) and strain would have been localized in the serpentinites if they had been present.

There is no relationship between the penetrative strain in the metagabbro and the numerous breccia zones. The latter result from postmetamorphic faulting which brought the gabbro-peridotite complex to its present high-level position.

\section{ACKNOWLEDGMENTS}

Support for this research by Special DAGS Grant-13 of the National Research Council of Canada is gratefully acknowledged. My colleagues, D.M. Carmichael and J.M. Dixon, provided stimulating discussions.

\section{REFERENCES}

Bonatti, E., Honnorez, J., Kirst, P., and Radicati, F., 1975. Metagabbros from the Mid-Atlantic Ridge at $06^{\circ} \mathrm{N}$ : Contact-Hydrothermal-Dynamic Metamorphism Beneath the Axial Valley: J. Geology, v. 83, p. 61-78.

deRoever, W.P., 1956. Sind die Alpinotypen PeridotitMassen vielleicht tektonisch verfrachtete Bruchstucke der Peridotitschale?: Geol. Rundschau, v. 46, p. 137-146.

Ramsay, J.G., 1967. Folding and fracturing of rocks: New York (McGraw-Hill).

Thayer, T.P., 1967. Chemical and structural relations of ultramafic and feldspathic rocks in alpine intrusive complexes. In Wyllie, P.J., (Ed.), Ultramafic and related rocks: New York (John Wiley \& Sons), p. 222-239.

1969. Peridotite-gabbro complexes as keys to Petrology of Mid-Oceanic Ridges: Geol. Soc. Am. Bull., v. 80 , p. $1515-1522$. 